\title{
THE RESULTS OF A NATIONAL INQUIRY INTO THE GROWTH OF PREMATURE CHILDREN FROM BIRTH TO 4 YEARS
}

\author{
BY \\ J. W. B. DOUGLAS and C. MOGFORD \\ From the Joint Committee of the Institute of Child Health (University of London), the Society of Medical Officers of \\ Health and the Population Investigation Committee
}

(RECEIVED FOR PUBLICATION JUNE 6, 1953)

In this paper we describe the growth of a national sample of premature children who have been followed up from birth to 4 years and who, throughout this period, have been contrasted with a closely matched group of children born at term. This is the second of three papers about these children; the first (Douglas and Mogford, 1953) described their health, and the third will describe their development and behaviour. Our present aims are as follows:

(a) To describe in what ways, if any, the growth of these premature children differs from the growth of their controls: $(b)$ to relate any differences that are found to the initial handicaps of the premature children, to the lengths of gestation, to the histories of pregnancy and to the heights and weights of their mothers; (c) to show the relative importance of prematurity as a cause of retarded growth in the whole population of young children in Great Britain.

\section{PREVIOUS STUDIES}

During the last 30 years many studies of the growth of premature children have been made, but the results are conflicting and it is still not possible to say how far, if at all, these children are physically handicapped in later life. Capper (1928) reported that they were retarded in growth even after the age of puberty; Hess, Mohr and Bartelme (1934) on the other hand found no reliable deficit in stature after 3 years of age. Illingworth (1939) found that a high proportion of the premature children attending an out-patient department were stunted and, in a later paper (Illingworth, Harvey and Jowett, 1950), showed that there is a direct relationship, that is, not limited to those children normally regarded as premature, between birth weight and subsequent physical development. Asher (1946) concluded that many premature children remain smaller than their fellows at least up to the age of 6 years. Drillien (1948) regarded the physical retardation of her sample of premature children as being a reflexion of the adverse environmental conditions associated with prematurity rather than a result of premature birth per se. Glaser, Parmelee and Plattner (1950) concluded that premature babies grow faster than mature babies during the first eight months of life and rapidly reduce their initial handicap.

This list of studies could be expanded many times without yielding any more consistent guide to the physical prognosis of prematurity. There appear to be two reasons for this. First, in all studies a relatively large proportion of surviving premature children could not be traced. For example, Capper, even though he enlisted the help of the Viennese police, lost $54 \%$ of the children he was looking for, Hess et al. lost $75 \%$ and Drillien $60 \%$. These great losses would not matter if it were certain that a representative sample of the premature children had been traced. But the type of children found will depend on the channels through which they have been sought: whether, for example, contacts were made mainly through welfare centres or mainly through out-patient departments of hospitals. Moreover, to judge from the experience of the present inquiry, an unduly high proportion of the defective children will be in institutions outside the authorities where they were born, and so will normally be lost to a local follow-up study. Of our 'main survey' sample, only three out of the 13 children who were living in institutions would have been found in the authority where they were born.

The second reason for the failure of earlier inquiries is that prematurely born children were in no instance compared with a suitable control group of heavier children. Thus Glaser, Parmelee and Plattner were content to compare the growth of their children in 1945-50 with Woodbury's norms of growth which were prepared in 1921. Hess et al., in an attempt to eliminate the effects of environment, 
tried to compare prematurely born children with their sibs. But only 105 brothers and sisters could be found to match with 250 premature children and they were, of course, of ten of different sex and always of different age from their matched pairs. Comparisons of growth are only meaningful if made between children of like sex and age, and accordingly Mohr and Bartelme were in fact comparing premature children not with their own brothers and sisters, but with children drawn from other families. In her Edinburgh inquiry, Drillien used as controls one in $\mathbf{1 0}$ of the children born in the hospital from which she drew her sample of premature births. But this control group, as she points out, did not allow for the fact that premature children tend to come from the poorer social classes, and it was not clear from her study how much of the retarded growth of these children was to be attributed to a poor environment and how much to prematurity.

\section{NATURE OF THE SAMPLE}

In the present study premature children from all parts of the country and from all social classes have been followed up from birth to 4 years and compared with a group of children weighing more than $5 \frac{1}{2} \mathrm{lb}$. at birth. These children were enrolled in 1946 when a Joint Committee of the Royal College of Obstetricians and Gynaecologists and the Population Investigation Committee, with the help of medical officers of health and health visitors throughout the country, investigated all confinements taking place in England, Wales and Scotland during the first week of March in that year (Royal College of Obstetricians and Gynaecologists and Population Investigation Committee, 1948). We have chosen as our sample of premature children all legitimate singletons who were notified to the Joint Committee during the survey week and who weighed $5 \frac{1}{2} \mathrm{lb}$. or less at birth. This standard of prematurity is now generally accepted for statistical purposes and has been used in most recent studies of the growth of premature children. For these reasons it has also been used in the present paper, though of course not all children of this weight range were premature in the sense that they were born before term.

Each premature child was paired with another child selected from the remaining legitimate singletons born during the first week of March, 1946, who was of the same sex and place in the family, who lived in the same locality, and whose mother was of the same age and came from a family in the same social group. Owing to the large numbers of children from whom we could draw, the majority of premature children could be closely matched for these characters (see Douglas and Mogford, 1953).
This comparative study of children born prematurely and at term is part of a much larger inquiry into the health, growth and development of a national sample of children. This larger inquiry (which will be referred to as the 'main survey') is mentioned here because it provides figures which allow us to estimate the importance of prematurity as a cause of retarded growth in the whole population of young children. The detailed planning of it has been described elsewhere (Douglas, 1951).

\section{INFORMATION AVAILABLE}

We have had considerable success in tracing the children in our sample, as Table 1 shows.

TABLE 1

LOSSES OF PREMATURE AND CONTROL PAIRS IN 1946-50

\begin{tabular}{|c|c|c|}
\hline \multicolumn{2}{|c|}{ Type of Loss } & Number of Pairs \\
\hline Unavoidable & $\begin{array}{l}\text { Death } \\
\text { Emigration }(1946-48) \\
\text { Emigration (1948-50) }\end{array}$ & $\begin{array}{l}173 \\
21^{*} \\
10^{*}\end{array}$ \\
\hline Avoidable & $\begin{array}{l}\text { Refusals } \\
\text { Untraced }\end{array}$ & $\begin{array}{l}6+ \\
2^{+}\end{array}$ \\
\hline \multirow[t]{2}{*}{ Alive and still in } & Survey & 464 \\
\hline & Tot & 676 \\
\hline
\end{tabular}

- Alive at time of emigration.

+ All known to be alive in 1950 .

These figures, however, underestimate the actual loss of information on the children's heights and weights because, for example, not all parents took their children to be weighed and measured at the required time. The extent of these additional losses and our checks on the accuracy of the measurements obtained will now be described.

The survey children were weighed at birth. Subsequently they were weighed and measured when they were 2 years old, and again when they were 4 years and 3 months. The weights were recorded in pounds and ounces, and the standing heights in feet and inches. It was hoped that these measurements would be taken for all the children at approximately the same time, that is to say in March, 1948, and June, 1950. But owing to difficulties in tracing them, some of their weights and heights were not obtained until several months later. In the following analysis we have excluded 2-year-old measurements taken later than June, 1948, and 4-year-old measurements taken later than September, 1950. A further source of loss was that some mothers, although willing to answer questions on their children's health, were unwilling or unable to take them to welfare centres to be weighed and measured. Since we have throughout this study treated our children as 
matched pairs, both children of a pair were excluded if information was missing for one of them. It will be seen in Table 2 that the number of pairs lost varies in each year and for each measurement.

TABLE 2

LOSS OF MEASUREMENT DATA

\begin{tabular}{|c|c|c|c|c|c|c|}
\hline \multirow{2}{*}{$\begin{array}{l}\text { Type of } \\
\text { Measure- } \\
\text { ment }\end{array}$} & \multirow[b]{2}{*}{$\begin{array}{c}\text { Age } \\
\text { (yrs.) }\end{array}$} & \multicolumn{4}{|c|}{ Measurements Available for } & \multirow{2}{*}{$\begin{array}{l}\text { Total } \\
\text { Number } \\
\text { of Pairs }\end{array}$} \\
\hline & & $\begin{array}{c}\text { Both } \\
\text { Members } \\
\text { of Pair }\end{array}$ & $\begin{array}{l}\text { Premature } \\
\text { Child } \\
\text { Only }\end{array}$ & $\begin{array}{l}\text { Con- } \\
\text { trol } \\
\text { Only }\end{array}$ & $\begin{array}{l}\text { Neither } \\
\text { Member } \\
\text { of Pair }\end{array}$ & \\
\hline Weight & $\frac{2}{4}$ & $\begin{array}{l}350 \\
363\end{array}$ & $\begin{array}{l}52 \\
43\end{array}$ & $\begin{array}{l}66 \\
47\end{array}$ & $\begin{array}{r}6 \\
11\end{array}$ & $\begin{array}{l}474 \\
464^{*}\end{array}$ \\
\hline Height & 2 & $\begin{array}{l}375 \\
372\end{array}$ & $\begin{array}{l}38 \\
43\end{array}$ & $\begin{array}{l}55 \\
37\end{array}$ & $\frac{6}{12}$ & $\begin{array}{l}474 \\
464^{*}\end{array}$ \\
\hline
\end{tabular}

- Ten children left the country between 1948 and 1950 (see Table 1).

These losses are considerable, but the figures in Table 3 suggest that they have not introduced any serious bias into the study. This table shows the mean weights and heights of children who were measured but whom we had to exclude because they were paired with others whose weights or heights were unknown. These means are closely similar to the means for children retained in the sample, as will be seen by comparing them with the figures in Table 4.

TABLE 3

MEAN WEIGHTS AND HEIGHTS OF CHILDREN EXCLUDED BECAUSE MATCHED PAIRS HAD NOT BEEN WEIGHED OR MEASURED

\begin{tabular}{lcccc}
\hline $\begin{array}{c}\text { Type of } \\
\text { Measurement }\end{array}$ & $\begin{array}{c}\text { Age } \\
\text { (vears) }\end{array}$ & $\begin{array}{c}\text { Premature } \\
\text { Children }\end{array}$ & Controk \\
\cline { 5 - 5 } Weight (lb.) & 2 & & $26 \cdot 60$ & $28 \cdot 85$ \\
Height (in.) & 4 & & $35 \cdot 53$ & $38 \cdot 14$ \\
& 2 & & $32 \cdot 76$ & $33 \cdot 76$ \\
& 4 & $39 \cdot 33$ & $40 \cdot 61$ \\
\hline
\end{tabular}

At each age the health visitors were asked to weigh the children without clothes, but it was evident from the answers given in 1948 that this had not always been done. In 1950, therefore, we specifically asked health visitors to state what clothes were worn, and it appeared that one or both members of 162 pairs were weighed when dressed. The mean weight of all the clothed children is $1 \mathrm{lb}$. greater than the mean for all those weighed unclothed, and accordingly this amount has been deducted from their weights in the following analysis. It was, however, only possible to make this adjustment in the 1950 weights as our information on clothing in the 1948 survey was certainly not complete. We feel, however, that this is unlikely to have reduced the value of the following comparisons because approximately the same number of premature children and controls were weighed with their clothes on, and we are concerned with a statement of means rather than with a description of individuals.

It is notoriously easy to make errors when taking and recording measurements. Accordingly we checked all the very high and very low measurements, referring back to the medical officers of health for verification all weights, heights and weight-height ratios that fell more than two standard deviations from the mean for the main survey sample.

In both surveys there was a tendency for weights and heights to be recorded as even rather than odd numbers. The reason would appear to be that although weights were asked for in pounds and ounces and standing heights in feet and inches, many health visitors gave them to the nearest pound or the nearest inch and, when they had to choose between an odd or an even number, tended to favour the latter. Since the same tendency is found for both premature children and their controls there is no reason to believe that the comparisons made in this paper are invalidated by this peculiarity of recording.

\section{RESULTS}

Comparison of Heights and Weights of Premature Children and Controls at Different Ages

There are no significant sex differences in the extent to which premature children lag behind their controls in either weight or height. Accordingly, since the pairs have been matched for sex, data for the.two sexes have been pooled in the following analysis.

The frequency distributions of the weights and heights of 4-year-old premature children and their controls are shown in Fig. 1. It will be seen that for both these measurements, the distribution of the premature children lies to the left of the distribution of the controls; that is to say, they are as a group lighter and shorter. The distributions are of the same shape, and there is no suggestion of a concentration of low measurements among a relatively small section of the premature children, the remainder being of normal weight and stature.

It is of interest that premature children of low birth weight appear to be no more stunted in later life than are those who were heavier at birth. Thus 109 of the premature children were 38 in. or less in height at 4 years. Of these, three had weighed $3 \frac{1}{2} \mathrm{lb}$. or less at birth, which is the number that would have been expected from the proportion of children of this low birth weight $(3 \cdot 1 \%)$ in the whole sample of surviving premature children. The number of surviving children of this weight is small, however, and this observation, which does not fit in with the opinion of many clinicians, needs to be confirmed.

Table 4 gives the average birth weights and the 

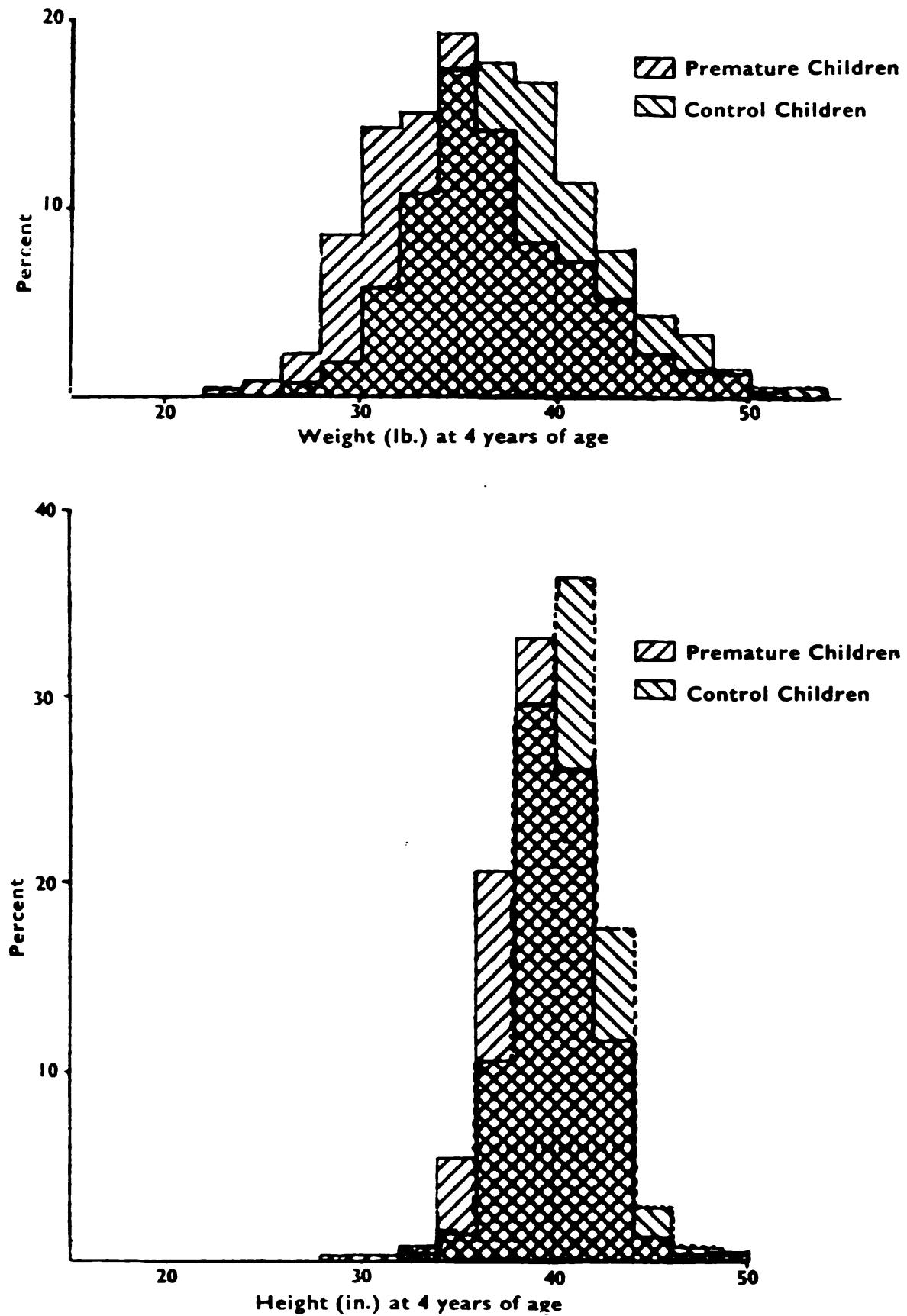

Fig. 1. - Above) Percentage distribution of weights of 4-year-old premature children and their controls. Fig. 1.-(Below) Percentage distribution of heights of 4-year-old premature children and their controls. 
average 2-year-old and 4-year-old heights and weights of the premature and control children. We have included in this and subsequent tables 11 premature children of known weight and height who either had birth injuries or congenital abnormalities.

TABLE 4

MEAN WEIGHTS AND HEIGHTS OF PREMATURE CHILDREN AND CONTROLS

\begin{tabular}{|c|c|c|c|c|c|}
\hline $\begin{array}{l}\text { Type of } \\
\text { Measure- } \\
\text { ment }\end{array}$ & $\underset{\text { (years) }}{\text { Age }}$ & $\begin{array}{l}\text { Premature } \\
\text { Children }\end{array}$ & Controls & Difference & $\begin{array}{c}\text { Number } \\
\text { of } \\
\text { Pairs }\end{array}$ \\
\hline Weight (lb.) & $\begin{array}{c}\text { At birth } \\
\frac{2}{4}\end{array}$ & $\begin{array}{r}4 \cdot 91 \\
26 \cdot 24 \\
35 \cdot 37\end{array}$ & $\begin{array}{r}7 \cdot 48 \\
28 \cdot 16 \\
37 \cdot 86\end{array}$ & $\begin{array}{l}2 \cdot 57=0.05 \\
1 \cdot 92=0 \cdot 23 \\
2 \cdot 48=0 \cdot 34\end{array}$ & $\begin{array}{l}474 \\
350 \\
363\end{array}$ \\
\hline Height (in.) & $\frac{2}{4}$ & $\begin{array}{l}32 \cdot 46 \\
39 \cdot 39\end{array}$ & $\begin{array}{l}33 \cdot 43 \\
40 \cdot 33\end{array}$ & $\begin{array}{l}0.97=0.15 \\
0.94=0.15\end{array}$ & $\begin{array}{l}375 \\
372\end{array}$ \\
\hline
\end{tabular}

At both 2 and 4 years, premature children are on the average lighter and shorter than their controls; they are approximately $2 \mathrm{lb}$. lighter at 2 years, and $2 \frac{1}{2} \mathrm{lb}$. lighter at 4 years, and at both these ages they are 1 in. shorter. These differences are highly significant. They may be put another way by saying that the weight of the average 4-year-old premature child is equivalent to that of a mature child of 3 years 6 months, and his height to that of a mature child of 3 years 8 months.

It will also be seen in Table 4 that although premature children are significantly less retarded in weight at 2 years than they were at birth, they lose ground between 2 and 4 years, and at the latter age are as much behind their controls in weight as they were when born. The deficit in height, on the other hand, remains constant between 2 and 4 years.

In Table 5 the measurements of the matched pairs have been grouped according to the birth weight of the premature member. Instead of giving separate figures for the measurements of the controls and the premature children, we have, in this and subsequent tables, given the average differences between their measurements. As the controls are in each group on the average taller or heavier, all these differences are positive; for convenience we will refer to them as the height or weight handicaps of the premature children.

TABLE 5

MEAN WEIGHT AND HEIGHT HANDICAPS OF PREMATURE CHILDREN OF DIFFERENT BIRTH WEIGHTS

\begin{tabular}{|c|c|c|c|c|c|c|}
\hline \multirow[b]{2}{*}{ Handicap } & \multirow[b]{2}{*}{ Age } & \multicolumn{5}{|c|}{ Birth Weight of Premature Child } \\
\hline & & $\begin{array}{l}4 \mathrm{lb} . \\
\text { or less }\end{array}$ & 4b. & $\begin{array}{c}4 \frac{1}{1}-5 \\
1 \mathrm{~b} .\end{array}$ & $\begin{array}{l}5-5 \frac{1}{16} \\
\text { lb. }\end{array}$ & $\begin{array}{c}\text { All } \\
\text { Pairs }\end{array}$ \\
\hline $\begin{array}{c}\text { Weight } \\
\text { (Ib.) }\end{array}$ & $\begin{array}{l}\text { At birth } \\
2 \text { years } \\
4 \text { years }\end{array}$ & $\begin{array}{l}4 \cdot 20 \\
3 \cdot 03 \\
2 \cdot 84\end{array}$ & $\begin{array}{l}3 \cdot 01 \\
2 \cdot 05 \\
2 \cdot 22\end{array}$ & $\begin{array}{l}2 \cdot 66 \\
1 \cdot 74 \\
2 \cdot 74\end{array}$ & $\begin{array}{l}2 \cdot 16 \\
1 \cdot 79 \\
2 \cdot 34\end{array}$ & $\begin{array}{l}2.57 \\
1.92 \\
2.48\end{array}$ \\
\hline $\begin{array}{c}\text { Height } \\
\text { (in.) }\end{array}$ & $\frac{2}{4}$ years & $\begin{array}{l}2 \cdot 30 \\
1 \cdot 34\end{array}$ & $\begin{array}{l}0.67 \\
0.80\end{array}$ & $\begin{array}{l}0.83 \\
0.92\end{array}$ & $\begin{array}{l}0.88 \\
0.91\end{array}$ & $\begin{array}{l}0.97 \\
0.94\end{array}$ \\
\hline
\end{tabular}

The initially large differences between the weight handicaps of these four groups of premature children have been greatly reduced by the time they: are 4 years old, but the smallest children at birth are still on the average the furthest behind their controls at this age. It will be noted that, whereas the premature children of birth weight $4 \mathrm{lb}$. or less tend to catch up throughout the first four years with their controls in weight and height, those weighing more than $4 \mathrm{lb}$. at birth catch up during the first two years only and thereafter lose ground in both these measurements.

We have so far considered only the average handicaps of the premature children; it is of practical interest, however, to see what proportion of them have eliminated their initial handicaps at different ages. By the time they are 2 years old, $31 \%$ have caught up with or surpassed their controls in weight and $44 \%$ have caught up with or surpassed them in height. At 4 years the comparable figures are $36^{\circ}$ and $44^{\%} \%$. In Table 6 the proportions of premature children who caught up with their controls at different ages have been related to their weight at birth.

TABLE 6

PROPORTION OF PREMATURE CHILDREN ELIMINATING WEIGHT OR HEIGHT HANDICAPS AT DIFFERENT AGES

\begin{tabular}{|c|c|c|c|c|c|c|}
\hline & \multirow{2}{*}{$\begin{array}{c}\text { Age } \\
\text { (yrs.) }\end{array}$} & \multicolumn{4}{|c|}{ Weight at Birth of Premature Child } & \multirow{2}{*}{$\begin{array}{r}\text { All } \\
\text { Birth } \\
\text { Weight }\end{array}$} \\
\hline & & $\begin{array}{l}4 \mathrm{lb} \text {. } \\
\text { or less }\end{array}$ & 4-4t & $\begin{array}{l}41-5 \\
\mathrm{lb} .\end{array}$ & $\begin{array}{l}5-5 \frac{1}{2} \\
\mathrm{lb} .\end{array}$ & \\
\hline $\begin{array}{l}\text { o who have } \\
\text { caught up } \\
\text { in weight }\end{array}$ & $\begin{array}{l}2 \\
4\end{array}$ & $\frac{21 \cdot 2}{41 \cdot 9}$ & $\begin{array}{l}34 \cdot 1 \\
40 \cdot 5\end{array}$ & $\begin{array}{l}34 \cdot 4 \\
32 \cdot 0\end{array}$ & $\begin{array}{l}30 \cdot 9 \\
35 \cdot 9\end{array}$ & $\begin{array}{l}31 \cdot 3 \\
35 \cdot 8\end{array}$ \\
\hline $\begin{array}{l}\text { owho have } \\
\text { caught up } \\
\text { in height }\end{array}$ & 2 & $\begin{array}{l}32 \cdot 4 \\
46 \cdot 9\end{array}$ & $\begin{array}{l}57 \cdot 1 \\
45 \cdot 0\end{array}$ & $\begin{array}{l}42 \cdot 0 \\
41 \cdot 6\end{array}$ & $\begin{array}{l}45 \cdot 0 \\
43 \cdot 7\end{array}$ & $\begin{array}{l}44 \cdot 4 \\
43 \cdot 5\end{array}$ \\
\hline
\end{tabular}

It appears that premature children who weighed $4 \mathrm{lb}$. or less at birth were at 2 years the least successful in eliminating their initial handicaps, but at 4 years they were the most successful in doing so. Although this relationship is not statistically significant, it is noted here because it supports the figures in Table 5 which suggest that the smallest premature children grow the fastest.

\section{Influence of Length of Gestation and Complications of Pregnancy}

So far the physical handicaps of premature children have been related only to their birth weight. We will now consider whether these handicaps are also related to the length of the gestation period and or to the health of their mothers during pregnancy. Owing to the relatively small number of pairs only two lengths of gestation were considered: those 
ending more than four weeks before the expected date of delivery and those ending later than this. For the same reason no attempt was made to consider the separate effects of different abnormalities of pregnancy, and we were content to divide the pairs into two groups, those where there was a reason (such as toxaemia, ante-partum haemorrhage or induction) for the premature delivery, and those where there was no reason.

The number of pairs available for this analysis was reduced because our information on the length of gestation and the complications of pregnancy was incomplete. In the original maternity survey these details were not asked for since we were then primarily interested in the functioning of the maternity services and in the costs of childbearing. Two years later, however, when it was decided to undertake the follow-up inquiry into prematurity, we attempted to make good this deficiency from the records of the midwives and maternity hospitals which had cared for our survey mothers. We were more successful in obtaining information than we had hoped but, owing to the incompleteness of some records, a number of pairs have had to be excluded. Thus out of 372 pairs for whom 4-year-old heights were known, 78 were excluded owing to lack of information; and out of the 363 pairs for whom 4-year-old weights were known, 79 were excluded. These exclusions have altered the average height handicap at this age from 0.94 in. to 0.93 in. and the average weight handicap from $2 \cdot 48 \mathrm{lb}$. to $2 \cdot 30 \mathrm{lb}$.; neither of these alterations is statistically significant. Table 7 shows the average weight and height handicaps of 4-year-old premature children related to the length of gestation and to whether or not there was a reason for premature delivery.

TABLE 7

WEIGHT AND HEIGHT HANDICAPS OF 4-YEAR-OLD PREMATURELY BORN CHILDREN RELATED TO LENGTH OF GESTATION AND ABNORMALITIES OF PREGNANCY

\begin{tabular}{|c|c|c|c|c|}
\hline & \multicolumn{2}{|c|}{$\begin{array}{l}\text { Reason for Premature } \\
\text { Delivery }\end{array}$} & \multicolumn{2}{|c|}{$\begin{array}{c}\text { No Reason for Premature } \\
\text { Delivery }\end{array}$} \\
\hline & $\begin{array}{c}\text { Born not } \\
\text { More than } \\
4 \text { Weeks } \\
\text { Early }\end{array}$ & $\begin{array}{l}\text { Born More } \\
\text { than } 4 \\
\text { Weeks } \\
\text { Early }\end{array}$ & $\begin{array}{c}\text { Born not } \\
\text { More than } \\
4 \text { Weeks } \\
\text { Early }\end{array}$ & $\begin{array}{l}\text { Born More } \\
\text { than } 4 \\
\text { Weeks } \\
\text { Early }\end{array}$ \\
\hline $\begin{array}{l}\text { Weight } \\
\text { Handicap } \\
\text { (lb.) } \\
\text { Height }\end{array}$ & $2 \cdot 26=0 \cdot 65$ & $0 \cdot 98=1 \cdot 24$ & $2 \cdot 44=0.56$ & $3 \cdot 20=0 \cdot 76$ \\
\hline $\begin{array}{l}\text { Handicap } \\
\text { (in.) }\end{array}$ & $0.89=0.33$ & $1 \cdot 22=0 \cdot 49$ & $0 \cdot 88=0 \cdot 25$ & $0 \cdot 89=0.45$ \\
\hline
\end{tabular}

At 4 years of age the height handicap is similar in each group. The weight handicap, on the other hand, appears to be smaller among the children whose premature delivery was explained by toxaemia, ante-partum haemorrhage or induction; in particular it is small for the children in this group who were born more than four weeks early: there were only 49 of these children, however, and their weight handicap is not significantly lower than that of children in the other three groups; it appears low owing to the inclusion of three premature children, two of whom were $12 \mathrm{lb}$. heavier than their controls at 4 years and one of whom was $14 \mathrm{lb}$. heavier. The history of these children is interesting. One of them has spent more than half the first four years of his life in hospital where he was treated for bilateral cataracts; there is no obvious explanation for his abnormally large weight; his mother is only $8 \mathrm{lb}$. heavier than the mother of his control and the control himself is of average weight. The mothers of the other two premature children were respectively $69 \mathrm{lb}$. and $22 \mathrm{lb}$. heavier than the mothers of the matched controls, though their heights were similar. The former had had a surgical induction of premature labour, and the latter a premature delivery shortly after a fall.

Further examination of the figures in Table 7, taking into account the weight handicap at birth. does not yield any more meaningful results, and we can find no statistically satisfactory evidence that either the length of gestation or the history of the pregnancy is related to the 4-year-old physical handicaps of these children.

\section{Handicaps of the Premature Child Related to his Mother's Height and Weight}

It is well known that the heights and to a lesser extent the weights of children are related to the heights and weights of their parents, and it has been shown that the mothers of premature children are on the average smaller than the mothers of those weighing more than $5 \frac{1}{2} \mathrm{lb}$. at birth (Baird, 1945; Thomson. 1951). Accordingly it is of interest to see how far differences in the size of premature children and their controls are reflected in differences in the size of their parents. The measurements of both parents were asked for in this survey, but, since the fathers' heights and weights were recorded estimates and not actual measurements, we have thought it better to consider only the maternal measurements in the following paragraphs. The majority of the mothers were weighed and measured when they attended for the school clinical examination of their children in March, 1952. They were weighed when wearing indoor clothes.

Fig. 2 shows the frequency distributions of the weights and heights of the mothers of premature children compared with similar distributions for the mothers of the controls. 

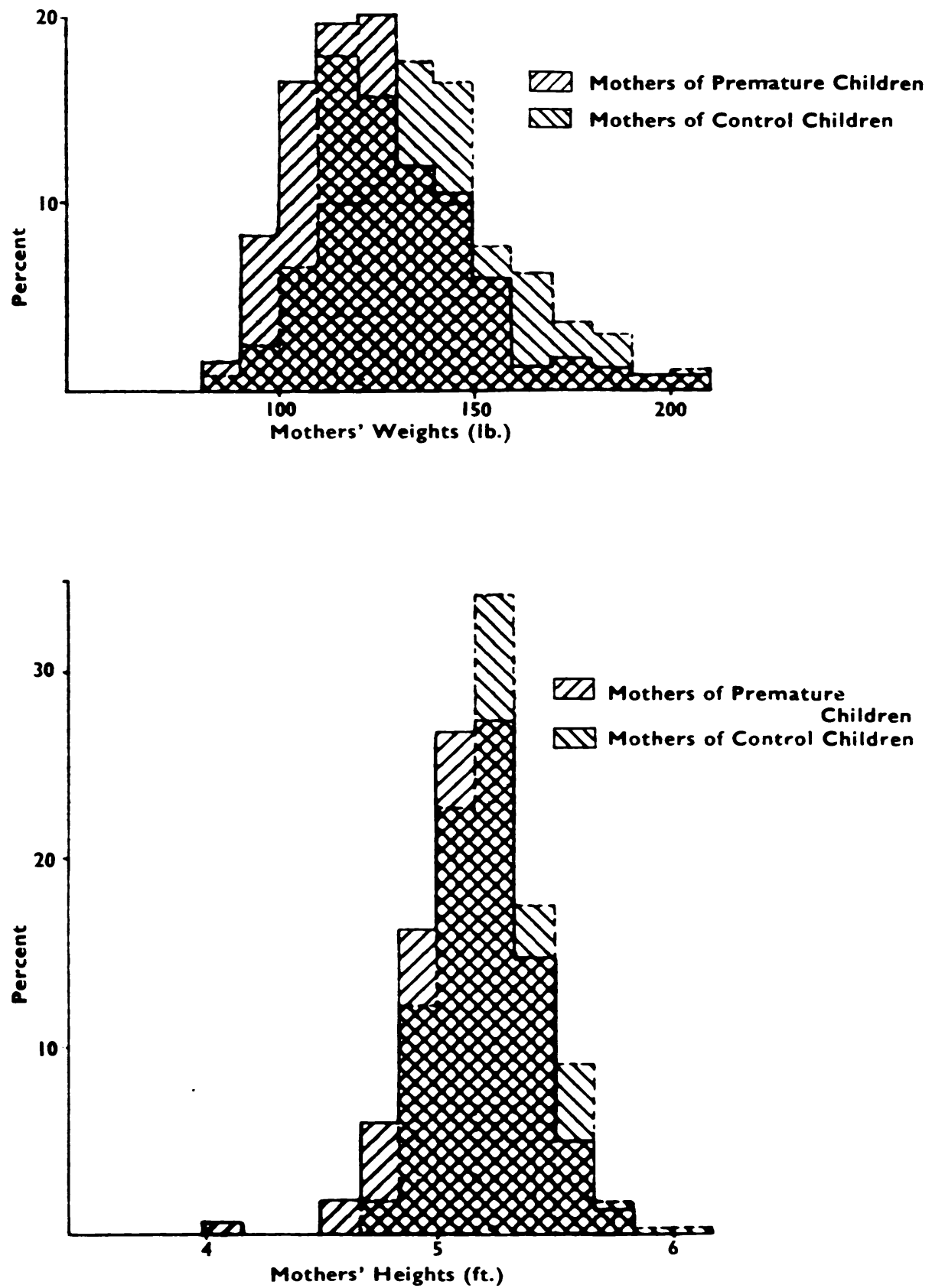

Fig. 2. (Above) Percentage distribut on of the weigt.ts of the mothers of premature children and of the mothers of their controls. Fig. 2.-(Belon) Percentage distribution of the weights of the motters of premature children and of the mothers of their controls.

For each measurement the distributions are similar in shape for the two types of mother, but those for the mothers of premature children lie to the left of those for the mothers of the controls, that is to say they tend to be lighter and shorter.

Both the height of the mother and the height of her 
child at 4 years are known for both members of 289 premature and control pairs. Among these the mothers of the premature children are 1.05 $=0.22$ in. smaller than the mothers of the controls, a figure that is closely similar to the difference in height between the children themselves, which for this group of 289 pairs is at 4 years $0 \cdot 89=0 \cdot 17$ in. There is a highly significant regression coefficient of -0.24 $(\mathrm{t}=5.57 \mathrm{n}=287 \mathrm{P}<0.001)$ relating the height differences between the pairs of children to the height differences between their mothers. By taking this factor into account, the variance of the height handicap of the premature children at four years is reduced by $11 \%$.

Similarly, the weight of both mothers and children is known for both members of 283 pairs. The mothers of the premature children are $8 \cdot 94=1 \cdot 74 \mathrm{lb}$. lighter than the mothers of the controls, whereas the average difference in weight between the children themselves is $2 \cdot 50=0 \cdot 37 \mathrm{lb}$. There is a small regression coefficient of $-0.027(t=2 \cdot 17 n=2810.05>P>0.02)$ relating the weight differences of the children to the weight differences of their parents, but the effect of this factor on the variance of the weight handicap of premature children at 4 years is negligible.

We have next divided these mothers as follows: (a) Those belonging to the pairs in which the premature child had by 4 years caught up with or surpassed his control in weight, and (b) those belonging to the pairs in which the premature child was still lagging behind in weight at this age. The weight differences between the pairs of mothers in these two groups are shown in the first line of Table 8. The figures in the second line were obtained after regrouping the mothers into those whose children had eliminated their initial height handicaps, and those whose children were still lagging behind their controls in height at 4 years.

\section{TABLE 8}

WEIGHT AND HEIGHT DIFFERENCES BETWEEN MOTHERS OF CONTROLS AND MOTHERS OF PREMATURE CHILDREN

\begin{tabular}{|c|c|c|}
\hline & $\begin{array}{c}\text { (a) } \\
\text { Premature } \\
\text { Children who } \\
\text { Have Caught Up }\end{array}$ & $\begin{array}{l}\text { (b) } \\
\text { Premature Children } \\
\text { Still Handicapped in } \\
\text { Height and Weight }\end{array}$ \\
\hline $\begin{array}{l}\text { Mothers' weight difference (lb.) } \\
\text { Mothers' height difference (in.) }\end{array}$ & $\begin{array}{l}-1 \cdot 92=2 \cdot 2 \\
-0 \cdot 12=0 \cdot 34\end{array}$ & $\begin{array}{l}-12 \cdot 6=2 \cdot 6 \\
-1 \cdot 82=0 \cdot 31\end{array}$ \\
\hline
\end{tabular}

The weight and height differences of the pairs of mothers in group (a) are not significantly different from zero and it appears that the mothers of the premature children who caught up, either in weight or in height, were drawn from the same weight or height populations as the mothers of the control pairs; on the other hand, the mothers of the premature children who did not catch up were drawn from a significantly lighter or shorter population.
As compared with the mothers of the controls. the women who suffered from abnormalities of pregnancy were on the average slightly taller and heavier than the women with no known cause for their premature delivery. Those with abnormal pregnancies were $7.0 \mathrm{lb}$. lighter and $0.84 \mathrm{in}$. shorter than the control mothers. whereas the corresponding figures for the mothers with normal pregnancies were $8.7 \mathrm{lb}$. and $1.4 \mathrm{in}$. Neither of these differences is significant.

It appears then that the height of a mother gives a better indication of the likely growth pattern of her premature baby than does the baby's weight at birth. the medical history of pregnancy, or the length of gestation, whether these three factors are considered separately or in combination.

\section{Contribution of Premature Children to the Total Number of Stunted and Linderweight Children in the Population}

Though the average height and weight handicaps of premature children are small, it seemed possible that these average figures hid an excess of stunted and underweight children who, in the aggregate. might make a serious contribution to the physically handicapped children in the population. This suggestion receives no support from a comparison of the weight and height distributions of the premature children and their controls (see Fig. 1); but it has important implications and needs a more detailed study, which is given here.

We have taken as being stunted or underweight those children who at both 2 and 4 years were more than 1 standard deviation below the mean of the main survey population (see page 437) for either weight or height or both. The limiting measurements were $25 \mathrm{lb}$. or less and 31 in. or less at 2 years and $33 \mathrm{lb}$. or less and 38 in. or less at 4 years. The proportion of children separated out in this way is shown in Table 9 for three groups, premature children, their controls and the mature children of the main sample.

It will be seen that approximately three times as many of the premature children as of the controls were stunted or underweight at both ages. It is also of interest that the proportion of children of this type in the main survey sample is significantly smaller than in the control sample. This latter finding is presumably explained by the fact (Douglas and Mogford, 1953) that the controls, being matched with the premature children, were drawn from poorer homes than the rest of the mature children born during the survey week, and were more often female.

Although premature children yield more than their share of those that are stunted or underweight, they 
TABLE 9

PERCENTAGE OF CHILDREN BELOW STANDARD FOR WEIGHT AND OR HEIGHT AT BOTH 2 AND 4 YEARS OF AGE

\begin{tabular}{|c|c|c|c|c|}
\hline $\begin{array}{l}\text { Mcasurement(s) } \\
\text { below Standard } \\
\text { in Both Years }\end{array}$ & $\begin{array}{c}\text { Premature } \\
\text { Children } \\
\left({ }^{\circ}{ }_{0}\right)\end{array}$ & $\begin{array}{l}\text { Controls } \\
\qquad\left({ }^{\circ}\right)\end{array}$ & $\begin{array}{c}\text { Main Sample } \\
\text { (Children of } \\
\text { Birth Weight } \\
\text { over } 5 \underline{1} \text { lb.) } \\
\left({ }_{0}\right)\end{array}$ & $\begin{array}{c}\text { All } \\
\text { Children } \\
\text { (i.e. Main } \\
\text { Sample Plus } \\
\text { Premature } \\
\text { Children) } \\
\left({ }_{0}^{\circ}\right)\end{array}$ \\
\hline \multirow{2}{*}{$\begin{array}{l}\begin{array}{l}\text { Weight only } \\
\text { Height only } \\
\text { Weight } \\
\text { beight }\end{array} \text { a } \\
\end{array}$} & $\begin{array}{r}15 \cdot 4 \\
6 \cdot 2\end{array}$ & $\begin{array}{l}6.8 \\
1.8\end{array}$ & $\begin{array}{l}5.0 \\
1.4\end{array}$ & $\begin{array}{l}5.4 \\
1.6\end{array}$ \\
\hline & $8 \cdot 4$ & $2 \cdot 3$ & $1 \cdot 7$ & $2 \cdot 0$ \\
\hline \multirow{2}{*}{$\begin{array}{l}\text { Total on below } \\
\text { standard } \\
\text { Number } \\
\text { ch of dren }\end{array}$} & $30 \cdot 0$ & 109 & $8 \cdot 1$ & $9 \cdot 0$ \\
\hline & 356 & 385 & $8053^{*}$ & 8409 \\
\hline
\end{tabular}

* When calculating the figures for the main survey sample, a correction has been made for the fact that, whereas all children in the upper social groups who were born in the first week of March, 1946, were enrolled in the survey, only one out of every four children in the manual working classes was enrolled (cf. Douglas, 1951). This correction is made by giving the former classes a weight of unity and the latter a weight of 4 . It should be noted that all the premature children born during the survey week were followed up, whatever the social class of their parents.

contribute only a relatively small proportion of the children of this type in the whole population. Thus, out of a total of 758 children who were below the standard for height and/or weight, $107(14 \cdot 1 \%)$ were prematurely born. This percentage may be compared with the incidence of surviving premature children in the sample which is $4.2 \%$. The 758 children below standard represent $9.0 \%$ of all the children born during the survey week and the removal of all prematurely born children from the sample would reduce this proportion by only $0.9 \%$. Even this figure overstates the importance of prematurity per se for it does not allow for the fact that premature children come from the poorer homes and include an excess of females. If the mature children in the main sample had been selected in the same way as the controls, there would have been a total of 986 stunted or underweight children in the population of whom $10.9 \%$ (and not $14.1 \%$ as given above) would have been premature.

The smallest premature children (of birth weight $3 \frac{1}{2} \mathrm{lb}$. or less) are no more likely to be stunted or underweight than are the heavier ones. Thus, out of 13 of these children of low birth weight, three were underweight and one was both stunted and underweight: this is the number that would have been expected from the experience of the whole group of premature children.

We have examined the medical histories of all these stunted and underweight children. Of the five most physically handicapped three were mongols and one had spina bifida. Otherwise there was no evidence of an excess of chronically ill children among them or of a high incidence of abnormalities of pregnancy or gestation.

\section{Comparisons Between Social Groups}

Since the premature children in this inquiry have been compared with controls who were drawn from similar homes and had parents of the same social group, the observed deficiencies in growth are unlikely to be explained by the association of prematurity with poverty. But it is of some interest to see whether the premature children reared in relatively prosperous homes were better able to reduce their initial handicaps than were those reared in poorer homes. As judged by the mean differences between the pairs in both weight and height, the children of the more prosperous parents (non-manual workers) have by 4 years of age made a proportionately greater reduction in their handicaps than the children in other groups. The former have by 4 years of age reduced their initial weight handicap by $37 \%$ and their 2-year-old height handicap by $17 \%$ whereas the latter have shown a slight increase in both their weight and height handicaps. These differences, however, are not statistically significant and are not supported by a comparison of the incidence of stunted and underweight children in the two groups. Using the standards given in the preceding section, the ratio of stunted and/or underweight premature children to stunted and/or underweight controls was $3 \cdot 5: 1$ in the non-manual working classes and 2.4:1 in the manual working classes. This difference again was not significant. There is no necessary conflict between these two findings which are at first sight contradictory. The proportion of premature children severely handicapped at 4 years might well be the same in all social groups, although on the average the premature child in a prosperous family has the greater chance of catching up. It is to be hoped that further information on this point will be forthcoming as we follow these children at later ages.

One further point of interest is that the mean difference in the heights of the mothers of the premature and control pairs is similar in each social group. For the non-manual workers it is $1.04=0.44$ in. and for the manual workers $1 \cdot 06=0 \cdot 26$ in.

\section{CONCLUSIONS}

Although, on the average, premature children do not reduce their initial weight handicaps during the first four years of their lives, or their two-year height handicaps between 2 and 4 years, there are considerable variations in the progress of individual children. It appears that the best guide to the growth of a premature baby is given by the height of his parents. Unfortunately we have only been able to 
consider the heights of the mothers as it was impossible to arrange for the fathers to be measured. But maternal height alone was of greater value in predicting the subsequent growth of our premature children than were birth weight, length of gestation, the medical history of the pregnancy, or any combination of these three factors

We do not wish to enter here into any detailed discussion of whether the shorter stature of the mothers of premature children arises from poor nutrition in early life or is genetically determined but the results of this inquiry suggest that the latter is the more probable explanation. We are doubtful about the importance of nutrition in this context because the mothers of our premature children were drawn from families that were closely similar in social and economic circumstances to those of the mothers of the controls. It may of course be objected that within the same social group the women with the poorest nutritional history (for example those coming from a poorer home than their husbands) are the most likely to have premature children and that our matching has not allowed for this. But this objection is hard to reconcile with the fact that the differences between mothers are just as large among - the relatively well-to-do pairs as among those from the manual worker group. It is hoped that the study of prematurity now being carried out by the National Birthday Trust Fund will throw more light on this problem. Whatever the outcome, it is clear that assessments of the physical handicaps of premature children can have little meaning unless they are related to the size of their parents; this was to be expected and is only emphasized here because, to our knowledge, there has been no previous attempt to establish such a relationship.

\section{SUMMARY}

This paper describes the growth of a national sample of premature children who have been followed up from birth to 4 years and who, throughout this period, have been contrasted with a closely matched group of controls.

On the average the premature children have not reduced their weight handicap between birth and 4 years, and have not reduced their height handicap between 2 and 4 years.

By 4 years of age, $36^{\circ}$ of premature children have caught up with or surpassed their controls in weight and $44 \%$ in height. There is a tendency for the smallest premature children at birth to be the most successful in eliminating their initial handicaps.

There is no statistically satisfactory evidence that premature children resulting from the shorter gestations or from complicated pregnancies differ in their rate of growth from the rest of the premature sample.
The mothers of premature children are on the average shorter and lighter than the mothers of the controls, and the premature children who are furthest behind their controls in weight or height tend also to be the ones whose mothers are furthest behind the mothers of the controls in these measurements.

The mothers of the premature children who, by 4 years have eliminated their initial weight or height handicaps, are as tall and as heavy as the mothers of the matched controls. In contrast the mothers of the children who are still lagging behind at this age are significantly smaller and lighter than the mothers of the controls.

Premature children yield more than their share of all children who are stunted or underweight. But removal of all premature children would make only a relatively small reduction in the numbers of children of this type in the whole population.

There is no satisfactory evidence that the premature children who come from the relatively well-todo families are any more successful in reducing their physical handicaps than those from poorer families.

This follow-up survey of premature children is being made by a joint committee of the Institute of Child Health (University of London), the Society of Medical Officers of Health and the Population Investigation Committee. The chairman of the Committee is Professor James Young, the vice-chairman Professor A. A. Moncrieff and the secretary Professor D. V. Glass. The Nuffield Foundation has financed this inquiry during the pre-school years, and a grant for continuing it in the primary school period has been made by the Board of Governors of The Hospital for Sick Children, Great Ormond Street, through the Institute of Child Health.

We wish to thank the chairman and members of the joint committee for their help and advice; the medical officers of health and the health visitors whose generous cooperation made this survey possible; and the mothers in all parts of the country who willingly answered numerous and detailed questions on their children's health.

Asher, C. (1946). Brit. med. J.. 1, 793.

Baird. D. (1945). J. Obstet. Ginaec. Brit. Emp.. 52. 339

Capper, A. (1928). Amer. J. Dis. Child. 35, 262.

Douglas, J. W. B. (1951). Lancet, 2, 443.

- and Mogfor 1, C. (1953). Brit. med. J., 1. 748.

Drillien, C. M. (1948). Archives of Disease in Childhood, 23.69.

Glaser, K.. Parm llee. A. H. and Plattner, E. B. (1950). Pediatrics, 5. 130 .

Hess, J. H., Mohr, G. J. and Bartelm?. P. F. (1934). The Physica! and Mental Growth of Prematurely Born Children. Chicago Univ. Press.

Illingworth. R. S. (1939). Archives of Disease in Childhood. 14. 121 - Harvey, C. C. and Jowett. G. H. (1950). Ibid., 25. 380

Roval College of Obstetricians and Gunzeologists and Population Investigation Committe?. (1948). Maternity in Great Britain. Investigatio

Thomson, A. M. (1951). Brit. J. Nutr.. 5. 158.

Woodbury, R. M. (1921). Statures and Weights of Children Linder 6 Years of Age. U.S Dept. of Labor. Children's Bureau Publication No. 87. Washington. 